\title{
Mortality and morbidity in children caused by falling televisions: a retrospective analysis of 71 cases
}

\author{
Servan Gokhan • Ozkan Kose • Ayhan Ozhasenekler • \\ Murat Orak • Mehmet Ustundag • Cahfer Guloglu
}

Received: 20 May 2010 / Accepted: 2 August 2010 /Published online: 4 November 2010

(C) The Author(s) 2010. This article is published with open access at Springerlink.com

\begin{abstract}
Background Femoral artery pseudoaneurysm following cardiac catheterization is a serious groin complication requiring careful assessment and prompt intervention.

Aims The risk of femoral artery pseudoaneurysm is estimated at 0.6 to $17 \%$ following diagnostic and interventional procedures.

Methods The clinical use of bedside ultrasonography as part of the physical examination by attending emergency physicians has increased significantly over recent years.

Results Bedside emergency department ultrasonography provides the clinician with critical information noninvasively, rapidly determining various anatomical structures.

Conclusions We present the case of a patient with femoral
\end{abstract}

The views expressed in this paper are those of the author(s) and not those of the editors, editorial board or publisher.

S. Gokhan

Accident and Emergency Department,

Diyarbakir Education and Research Hospital,

Diyarbakir, Turkey

O. Kose

Orthopaedics and Traumatology Clinic, Diyarbakir State Hospital,

Diyarbakir, Turkey

\section{A. Ozhasenekler}

Emergency Clinic, Diyarbakir State Hospital,

Diyarbakir, Turkey

M. Orak $\cdot$ M. Ustundag $\cdot$ C. Guloglu

Department of Emergency Medicine,

Dicle University School of Medicine,

Diyarbakir, Turkey

O. Kose $(\bowtie)$

Pinarbasi mh. 758.sk,

Ozpinarlar Nazlibahce Evleri,

A Blok D:8 Konyaalti,

Antalya, Turkey

e-mail: drozkankose@hotmail.com artery pseudoaneurysm detected by bedside emergency department ultrasonography secondary to angiographic catheterization.

Keywords Wounds and injuries · Television .

Home accidents $\cdot$ Child

\section{Introduction}

Accidents are a major cause of death and disability in children. Accidents can take place in a wide variety of environments and settings; however, the home, which people regard as the safest place, is the most likely location [1]. Home accidents comprise $35 \%$ of all unintentional injuries in childhood, and the majority of victims are toddlers and pre-school children [2].

Televisions (TV) have become ubiquitous in households all around the world [3-5]. Over the past several years, TVs have grown larger in size and shape, which has made them unstable and susceptible to toppling [6, 7]. Falling TVs have created a potential risk for significant injury to children in households. However, despite the danger, only a few studies have been reported in the literature regarding this source of risk [1, 311]. Furthermore, several home safety guidelines for parents do not include how to prevent TV-related injuries [12, 13].

The purpose of this study was to quantify injuries in children that result from toppled televisions and to highlight the significance of this mechanism of injury.

\section{Materials and methods}

This is a retrospective chart review study for which we collected data from our emergency department's digital patient database for the September 2008-September 2009 period. This study was conducted in an urban community 
Table 1 Age and gender of the patients

\begin{tabular}{llll}
\hline Age (months) & Girls & Boys & Total \\
\hline$<12$ & 0 & 1 & 2 \\
$12-24$ & 4 & 9 & 13 \\
$25-36$ & 5 & 20 & 25 \\
$37-48$ & 4 & 3 & 7 \\
$49-60$ & 4 & 9 & 13 \\
$61-72$ & 1 & 5 & 6 \\
$73-84$ & 3 & 2 & 6 \\
$>84$ & 0 & 1 & 1 \\
Total & 21 & 50 & 71 \\
\hline
\end{tabular}

general emergency department (ED). All children under 15 years of age who presented to the ED with injuries casued by a falling television were included in this study. Patients were identified and selected from the digital database using the chief complaint upon arrival. Demographic information, injured body region and diagnosis, surgical intervention, admission to the intensive care unit (ICU), Glasgow Coma Scale (GCS) score, length of hospital stay (LOS), in-hospital mortality, and disposition at hospital discharge were analysed. A descriptive analysis of the continuous and categorical data was performed using proportions, frequency distributions, means, and standard deviations. No statistical analysis was performed in this descriptive study.

\section{Results}

During the 12-month period under investigation, 3,856 children were admitted to our ED with injuries sustained at home. Of these 3,856 admissions, 71 (1.8\%) were becasue of TV-related injuries, and thus these patients were included in this analysis. There were $50(70.4 \%)$ male and 21 $(29.6 \%)$ female patients. The mean age was $39.79 \pm 20.14$ months (SD), with more than half $(53.5 \%)$ of the children aged 12 to 36 months. The age and gender distribution of patients is presented in Table 1 .

Almost three-quarters of the children (49/71) sustained various head and facial injuries. The most common site for a scalp hematoma was the occipital region (55\%), followed by the temporal, frontal, and parietal regions. The most common site for a scalp laceration was the frontal region (57\%), followed by the temporal, occipital, and parietal regions. There were 18 skull fractures ( 8 occipital bone, 4 temporal bone, 3 frontal bone, and 3 parietal bone). Traumatic brain injury occurred in 14 patients (4 subarachnoid bleeding, 1 epidural hematoma, 1 subdural hematoma, and 8 cerebral contusions). The average GCS score was 13.3 (range, 3-15) in head trauma patients.

Thirty patients had extremity injuries, of which 22 were soft tissue contusions. One patient had a skin laceration over the midfoot that was sutured in the ED. There were seven patients with fractures, which were all treated with casting and/or closed reduction.

Thoracic injury occurred in 13 patients. Two patients had costal fracture without associated paranchymal injury on thoracic CT. The remaining 11 patients had chest wall contusions.

Ten patients (14\%) sustained abdominal trauma. Two of them had superficial skin lacerations over the abdominal wall that did not reach the intra-abdominal cavity. Skin lacerations were sutured in the ED. One patient had a minor liver laceration, and two patients had free fluid in the abdomen detected with ultrasonography. These patients were followed up without surgical intervention.

Fifty-four patients were discharged within $24 \mathrm{~h}$ after admission. The mean length of stay was $15.6 \mathrm{~h}(1-24 \mathrm{~h})$ in

Table 2 Distribution and description of injured body regions. The number of injuries may add up to more than the number of cases because of multiple injuries

Injured body region Number Description of the injuries of cases

Head and facial injuries

*Scalp and facial injuries

*Skull fractures

*Traumatic brain injury

Chest injuries

Abdominal injuries

Extremity injuries

*Upper extremity

*Lower extremity
31 patients, scalp hematoma 14 patients, scalp laceration 6 patients, nasal contusion

2 patients, forehead laceration 1 patient, lip laceration

8 patients, nondisplaced linear skull fracture

10 patients, basilar skull fracture

4 patients, subarachnoid bleeding

1 patient, epidural hematoma

1 patient, subdural hematoma

8 patients, cerebral contusion

2 patients, rib fracture

11 patients, chest wall contusion

1 patient, grade 1 liver laceration

2 patients, abdominal wall laceration

7 patients abdominal wall contusion

17 patients, soft tissue injuries 1 patient, clavicular fracture 1 patient, radius distal torus fracture 5 patients, soft tissue injuries 1 patient, skin laceration over midfoot 2 patients, closed tibia fracture 2 patients, closed metatarsal fracture 1 patient, closed femur fracture 
these patients. Sixteen patients were hospitalised, and 14 of them required follow-up in the ICU. All hospitalised patients had head injuries. Two patients (one with an epidural hematoma and one with a subdural hematoma) underwent surgical intervention. Four patients with subarachnoid bleeding died (mean age, 30.25 months, range 27-31). One of them died immediately upon arrival, and the other three died in the ICU. The mean LOS was 71.25 $\mathrm{h}$ (range, $48-168 \mathrm{~h}$ ) in the hospitalised patients. The overall mortality rate was $5.6 \%$. All patients were discharged without neurological deficits. Table 2 shows the distribution of injured body regions and their description.

\section{Discussion}

Most accidents take place in the home environment, especially in toddlers and pre-schoolers as they spend most of their time there $[1,2,11]$. This study showed that children aged 12 to 36 months of both genders had the highest overall injury rate resulting from TV-related injuries. This coincides with developmental achievements such as independent mobility and exploratory behaviours of children. Children's relative lack of coordination at this stage of development and their still undeveloped cognitive hazard awareness and avoidance skills are the major reasons for the accumulation of injuries at this age [14]. Previous studies on TV-related injuries have had comparable results to those of our study $[1,6,8]$. Discala et al. reported that more than half $(57.4 \%)$ of the children were boys, and more than three quarters $(76.0 \%)$ were 1 to 4 years of age [6]. Similarly, Yahya et al. reported that 7 out of 18 children with TVrelated head injuries were younger than 36 months of age, and more severe injuries occurred in this age group in their series [10]. Although home accidents can occur in all children, current evidence indicates that this specific mechanism of injury particularly affects boys younger than 36 months of age.

Previous retrospective descriptions and a prospective study have confirmed that a TV tip-over usually occurs when a curious toddler attempts to climb onto furniture, typically a dresser, on which the TV sits, causing the furniture and the TV to fall onto the child $[1,5]$. Cathode ray tube TVs are not stable due to the imbalance of the intrinsic weight distribution of their design [6,7]. The center of gravity is very close to the anterior heavy glass screen. Dotchin et al. constructed a static model of a climbing child to simulate a TV tip-over and investigated how much weight was enough to topple a TV. Suprisingly, they found that $90 \%$ of the accessible televisions could be tipped by a child 4 years of age with weight in the 90th percentile [7].
Head and facial injuries were most commonly encountered with this mechanism of injury. Sikron et al. reported that nearly three-quarters of the children $(73.3 \%)$ sustained head/neck injuries, with almost half of these having a definite traumatic brain injury [3]. Our results and the other relevant studies supported this evidence $[5,11]$. There may be two reasons; either the TV falls onto the child's head, or the child hits his head on the ground during the fall. Both mechanisms of injury seem to be reasonable. We further analysed our data and found that occipital and frontal lesions, involving scalp haematomas, lacerations, and cranial fractures, were more common than lesions in other head regions. Probably, the child falls supine, facing the TV during the fall. The presence of frontal lacerations, nasal contusions, and forehead and lip lacerations are indications of the first scenario, while the presence of occipital hematomas and fractures point to the second.

Mortality and substantial long-term sequelae in TVrelated injuries can be attributed to traumatic brain injuries $[9,10]$. Four patients with subarachnoid bleeding all died in the hospital. Other injuries, including those of the abdomen, chest, and extremities, were mild to moderate in this study. Bernard et al. reported the highest mortality rate (38.3\%) among studies concerning TV-related injuries. However, crush type injuries were also responsible for half of the mortality in their study [8]. Therefore, victims of TV-related injury should be carefully examined for possible fatal abdominal and thoracic injuries.

This study has several limitations. As a retrospective study, we could not obtain a detailed history from the parents at the time of admission. We do not know the TV screen sizes, what the TVs were placed on, and the circumstances surrounding the injury scene. Furthermore, data were extracted from our digital patient database, and some cases may have been missed, which may have affected the results. Prospective studies are necessary to have a more realistic understanding of the mechanism of injury.

In conclusion, falling TVs may cause significant morbidity and mortality in children, particularly those younger than 3 years old. Head and facial injuries are the most commonly encountered, followed by injuries to the extremities. Traumatic brain injury is the major cause of death. Preventive measures taken in the home and, more importantly, increased awareness of this potential risk of injury by the parents are the key solutions to this problem.

\section{Conflicts of interest None.}

Open Access This article is distributed under the terms of the Creative Commons Attribution Noncommercial License which permits any noncommercial use, distribution, and reproduction in any medium, provided the original author(s) and source are credited. 


\section{References}

1. Scheidler MG, Shultz BL, Schall L et al (2002) Falling televisions: The hidden danger for children. J Pediatr Surg 37:572-575

2. Tsoumakas K, Dousis E, Mavridi F et al (2009) Parent's adherence to children's home-accident preventive measures. Int Nurs Rev 56 (3):369-374

3. Sikron F, Glasser S, Peleg K (2007) Children injured following TV tipovers in Isreal, 1997-2003. Child Care Health Dev 33:45-51

4. Murray KJ, Griffin R, Rue LW 3rd et al (2009) Recent trends in television tip over-related injuries among children aged $0-9$ years. Inj Prev 15(4):240-243

5. Ota FS, Maxson RT, Okada PJ (2006) Childhood injuries caused by falling televisions. Acad Emerg Med 13(6):700-703

6. DiScala C, Barthel M, Sege R (2001) Outcomes from television sets toppling onto toddlers. Arch Pediatr Adolesc Med 155:145-148

7. Dotchin SA, Gordon KE (2007) The terrible truth about toppling televisions. Paediatr Child Health 12(3):221-224

8. Bernard PA, Johnston C, Curtis SE et al (1998) Toppled television sets cause significant pediatric morbidity and mortality. Pediatrics 102:E32

9. Jea A, Ragheb J, Morrison G (2003) Television tipovers as a significant source of pediatric head injury. Pediatr Neurosurg 38:191-194

10. Yahya RR, Dirks P, Humphreys R et al (2005) Children and television tipovers: A significant and preventable cause of longterm neurological deficits. J Neurosurg 103(3):219-222

11. Gottesman BL, McKenzie LB, Conner KA et al (2009) Injuries From furniture tip-overs among children and adolescents in the United States, 1990-2007. Clin Pediatr (Phila) 48(8):851-858

12. The Safety Guide. Home Safety Council Web site. Available at: http://www.homesafetycouncil.org/SafetyGuide/sg_security_w001. asp. Accessed March 16, 2010
13. Home and Garden Safety Checklist. The Royal Society for the Prevention of Accidents Web site. Available at: http://www.rospa. co.uk/homesafety/advice/general/checklists.htm Accessed March $16,2010$.

14. Agran PF, Anderson C, Winn D et al (2003) Rates of pediatric injuries by 3 -month intervals for children 0 to 3 years of age. Pediatrics 111(6 Pt 1):e683-e692

Servan Gokhan, MD He is an Emergency Medicine specialist, chief physician at Diyarbakir Education and Research Hospital, and a multiple trauma co-ordinator.

Ozkan Kose, MD He is a consultant surgeon in Orthopaedics and Traumatology, and a member of the staff at Diyarbakir State Hospital.

Ayhan Ozhasenekler, MD $\mathrm{He}$ is an Emergency Medicine specialist, chief physician at Diyarbakir State Hospital, and a multiple trauma co-ordinator.

Murat Orak, MD $\mathrm{He}$ is an Emergency Medicine specialist and Assistant Professor at Dicle University School of Medicine, Emergency Department.

Mehmet Ustundag, MD He is an Emergency Medicine specialist and Assistant Professor at Dicle University School of Medicine, Emergency Department.

Cahfer Guloglu, MD $\mathrm{He}$ is an Emergency Medicine specialist, Associate Professor at Dicle University School of Medicine, and head of the Emergency Department. 